\title{
Impact of Cardiac Catheterization on the Outcome of Extracorporeal Membrane Oxygenation (ECMO) After Congenital Cardiac Surgery - Two Centers Experience
}

Gaser Abdelmohsen ( $\nabla$ gaser_abdelmohsen81@yahoo.com )

Cairo University Kasr Alainy Faculty of Medicine https://orcid.org/0000-0002-0361-2921

Jameel Al-Ata

King Abdulaziz University Hospital

Naif Alkhushi

King Abdulaziz University Hospital

Saud Bahaidarah

King Abdulaziz University Hospital

Hysam Baho

King Faisal Specialist Hospital and Research Centre - Jeddah

Mohamed Abdelsalam

Benha University Faculty of Medicine

Samia Bekheet

Cairo University Kasr Alainy Faculty of Medicine

Wejdan Ba-Atiyah

King Faisal Specialist Hospital and Research Centre - Jeddah

Abdulhadi Alghamdi

King Abdulaziz University Hospital

Ahmed Fawzy

King Abdulaziz University Hospital

Ahmed Elakaby

Al-Azhar University Faculty of Medicine

Osman Al-Radi

King Abdulaziz University Hospital

Ahmed Jamjoom

King Faisal Specialist Hospital and Research Centre - Jeddah

Ahmed Elassal

Zagazig University Faculty of Human Medicine

Mohammad Shihata

King Faisal Specialist Hospital and Research Centre - Jeddah 


\section{Zaher Zaher}

King Abdulaziz University Hospital

Mohamed Mashali

Cairo University Kasr Alainy Faculty of Medicine

Ahmed Dohain

Cairo University Kasr Alainy Faculty of Medicine

\section{Research Article}

Keywords: extracorporeal membrane oxygenation (ECMO), cardiac catheterization, congenital cardiac surgery, Two centres experience

Posted Date: February 8th, 2021

DOl: https://doi.org/10.21203/rs.3.rs-167694/v1

License: (c) (i) This work is licensed under a Creative Commons Attribution 4.0 International License. Read Full License 


\section{Abstract}

Background: Cardiac catheterization performed for patients supported by extracorporeal membrane oxygenation (ECMO) after congenital heart surgery may affect their clinical outcome, yet its effect in this group of patients is not adequately studied. The objective of this study was the evaluation of the impact of cardiac catheterization on successful weaning from ECMO support and survival after congenital heart surgery and determining predictors that influence successful weaning.

Methods : This is a retrospective cohort study conducted on paediatric patients underwent cardiac catheterization while on ECMO support after congenital heart surgery in two cardiac centres from November 2012 till February 2020. Predictors of successful weaning from ECMO support were studied using univariable and multivariable logistic regression analysis.

Results: Out of 141 patients received ECMO support after congenital cardiac surgery, 60 patients underwent 60 cardiac catheterizations (31 diagnostic and 29 interventional). The median age was 6.5 months (range 4 days -20 years), median weight was $5 \mathrm{~kg}$ (range $2-53 \mathrm{~kg}$ ). Thirty-four patients $(56.7 \%)$ underwent successful decannulation from ECMO support and 22patients (36.3\%) survived to hospital discharge. Predictors of successful weaning from ECMO support and survival were shorter duration on ECMO support, absence of bleeding tendency, early cardiac catheterization, and biventricular physiology.

Conclusion: Cardiac catheterization is feasible with acceptable risks for patients receiving ECMO after congenital heart surgery. The shorter duration on ECMO support may have a significant influence on successful weaning from ECMO and survival after congenital heart surgery. Early cardiac catheterization could also influence the successful weaning from ECMO.

\section{Introduction}

Extracorporeal membrane oxygenation (ECMO) considered one of the therapeutic modalities in the setting of critical congenital heart diseases. After congenital heart surgery, ECMO support could be lifesaving especially in cases of unsuccessful weaning from cardiopulmonary bypass, extracorporeal cardiopulmonary resuscitation, low cardiac output status or severe desaturation due to obstructed surgical shunts. ECMO can provide cardiorespiratory support until recovery of the cardiorespiratory system, correction of residual cardiac lesions or establishing of an alternative treatment option e.g. cardiac transplantation or ventricular assisted device)[1-4].

Although the outcome of cardiac patients connected to ECMO support has been markedly improved, still more than $25 \%$ of these patients might have a failure of weaning from ECMO support $[1,2,5,6]$. After congenital heart surgery, end-organ damage, significant cardiac dysfunction and significant residual cardiac lesions were known as undesirable risk factors that preclude successful weaning from ECMO and survival[7-9]. 
In some instances, identification of the cause of clinical deterioration necessitating the need for ECMO support after congenital heart surgery could not be feasible by non-invasive modalities like echocardiography. In these patients, cardiac catheterization could be helpful for identification of residual lesions requiring subsequent surgery or intervention during the same catheterization procedure. Data about the risk and outcome of catheterizations in this group of patients are growing and variable[ $[1-3,5$, $10,11]$.

The main objectives of this study were evaluation of the effect of cardiac catheterization performed for patients receiving ECMO support after congenital cardiac surgery on the clinical outcome, and to determine the factors that could affect successful weaning from ECMO support and survival among this group of patients.

\section{Methodology}

In this cohort, we retrospectively reviewed the data of patients underwent cardiac catheterization while on ECMO support after congenital heart surgery in two cardiac centres from November 2012 till February 2020. Demographic, surgical, echocardiographic, ECMO, cardiac catheterization and outcome data were collected from patients' medical records.

\section{ECMO support}

All patients underwent central cannulation through median sternotomy except one patient who performed femoral arteriovenous cannulation. ECMO flow started at 100-150 ml/kg then adjusted based on hemodynamic status, blood gases results, lactate levels and end-organ perfusion.

Data collected were an indication of ECMO, duration, complications, the fate of decannulation/ weaning from ECMO support (either successful or not). Successful weaning from ECMO was defined if the patient maintained hemodynamic for $>48$ hours after decannulation of ECMO.

Indications for ECMO support were inability to wean from cardiopulmonary bypass, after extracorporeal cardiopulmonary resuscitation (ECPR), low cardiac output and persistently low oxygen saturation after maximum respiratory support. The reported ECMO complications were bleeding tendency, pulmonary injury (pulmonary haemorrhage, atelectasis or consolidation in chest roentgenograms), limb ischemia, neurological and renal injury. The neurological injury was considered if clinical or radiological evidence of acute brain insult (seizers, haemorrhage, infarction) is present while renal injury was considered if elevated serum creatinine or the need for renal replacement therapy is coexisting.

\section{Cardiac catheterization.}

Data regarding cardiac catheterization included; type of cardiac catheterization, time from ECMO to cardiac catheterization, type of procedure performed, complications and vascular access. If more than 
one interventional procedure was performed during the same catheterization it was considered as a single procedure. Patients were then subdivided into 2 groups, early (within 24 hours) and late ( $>24$ hours) of ECMO connection. Outcome data included weaning from ECMO, survival to hospital discharge, duration of mechanical ventilation, the total duration of admission in Intensive care unit and hospital length of stay.

\section{STATISTICAL ANALYSIS}

IBM SPSS Statistics for Windows, version 26 (IBM Corp., Armonk, N.Y., USA) software program used for statistical analysis. Categorical variables were expressed as numbers or numbers and percentages, Numeric variables were presented in median and interquartile range (25th -75th percentiles). Comparisons between groups were tested using $\chi 2$ and Mann-Whitney $U$ tests for categorical and numeric variables respectively. Predictors of successful weaning from ECMO were evaluated using logistic regression analysis. Variables that found to be statistically significant after univariate logistic regression were incorporated into a stepwise multivariate logistic regression model. Survival was examined after ECMO decannulation using Kaplan Meier survival analysis. Statistical significance was considered if $\mathrm{P}$-values $<0.05$.

\section{Results}

\section{Patients' demographic}

During the study time frame, 141 patients had received ECMO support after congenital heart surgery. Of these, 60 patients (42\%) underwent 60 cardiac catheterization procedures. The median age was 6.5 months (range 4 days - 20 years), median weight was $5 \mathrm{~kg}$ (range 2-53 kg). Single ventricle physiology was reported in $51.6 \%$ of patients while hypoplastic left heart variants reported in 13 patients $(21.6 \%)$. Twenty-three patients (38.3\%) underwent univentricular stage 1 palliation and 26 patients (43.3\%) underwent complete biventricular repair. Table 1 summarizes characteristics of the studied patients. 
Table 1

Patients' characteristics

\section{Patients' characteristics}

Age, days

Weight, Kg

Male/female, $n$ (\%)

Syndromes, $n(\%)$

Non syndromic

Trisomy 21

DiGeorge

William

\section{Ventricular physiology, $n$ (\%)}

Single ventricle

Biventricular

\section{Diagnosis, $\mathrm{n}(\%)$}

Hypoplastic left heart variants

Hypoplastic right heart variants

Fallot+/- pulmonary atresia

Complex CHD

TGA+/- VSD

DORV

Aortic/LVOT obstruction

Others (ALCAPA, mitral diseases, truncus)

\section{Primary cardiac Surgery, n (\%)}

Univentricular stage 1 palliation/BTS/PAB $(n=60)$

196(46-870)

$5(3-10)$

$28(46.7) / 32(53.3)$

$52(86.7)$

$4(6.7)$

$1(1.7)$

$3(5)$

$31(51.7 \%)$

$29(48.3 \%)$

$13(21.7)$

7(11.7)

$10(16.7)$

9 (15)

$4(6.7)$

5 (8.3)

$8(13.3)$

$4(6.7)$

$23(38.3)$

Abbreviations: CHD; congenital heart diseases, TGA; transposition of great arteries, VSD; ventricular septal defect; DORV; Double outlet right ventricle, LVOT; left ventricle outflow tract, ALCAPA; Aberrant left coronary artery from pulmonary artery, PAB; pulmonary artery banding; MBTS; Modified Blalock Taussig shunt ,PCPC; Bidirectional cavopulmonary connection, TCPC; Total cavopulmonary connection, RACHS-1; Risk Adjustment for Congenital Heart Surgery. 


\begin{tabular}{|ll|}
\hline Patients' characteristics & $(\mathbf{n}=60)$ \\
\hline BCPC/Glenn shunt & $2(3.3)$ \\
\hline TCPC/Fontan shunt & $6(10)$ \\
\hline Biventricular palliative surgery (PAB, MBTS) & $3(5)$ \\
\hline Biventricular complete repair & $26(43.3)$ \\
\hline RACHS-1 score, $\mathbf{n}(\%)$ & \\
\hline $2-3$ & $30(50)$ \\
\hline $4-5$ & $14(23.3)$ \\
\hline 6 & $16(26.7)$ \\
\hline $\begin{array}{l}\text { Abbreviations: CHD; congenital heart diseases, TGA; transposition of great arteries, VSD; ventricular } \\
\text { septal defect; DORV; Double outlet right ventricle, LVOT; left ventricle outflow tract, ALCAPA; Aberrant } \\
\text { left coronary artery from pulmonary artery, PAB; pulmonary artery banding; MBTS; Modified Blalock }\end{array}$ \\
$\begin{array}{l}\text { Taussig shunt ,PCPC; Bidirectional cavopulmonary connection, TCPC; Total cavopulmonary } \\
\text { connection, RACHS-1; Risk Adjustment for Congenital Heart Surgery. }\end{array}$ \\
\hline
\end{tabular}

\section{ECMO support}

The median interval of ECMO from cardiac surgery was 2 hours (ranging from 0 hours to 11 days) and the median interval of cardiac catheterization from initiation of ECMO support was 20 hours (ranging from 1 hour to 170 hours). Regarding indication for ECMO support; 27 patients (45\%) required ECMO support after extracorporeal cardiopulmonary resuscitation (ECPR), 19 patients (31.7\%) due to failure to wean from cardiopulmonary bypass (CPB) and 13 patients $(21.7 \%)$ due to low cardiac output status.

Regarding complications related to ECMO support, the bleeding tendency (significant oozing from the surgical wound and chest tube drainage $>5 \mathrm{ml} / \mathrm{kg} / \mathrm{hour}$ ) was reported in $43.3 \%$ of patients, pulmonary injury in $36.7 \%$, acute kidney injury in $28.3 \%$, neurological insults in $28.3 \%$ while vascular access complications related to cardiac catheterization (deep venous thrombosis and arterial thrombosis) were reported in $18.3 \%$ of patients.

The median duration on ECMO support was 5 days. Thirty-four patients $(56.7 \%)$ were successfully weaned from ECMO support while 22 patients (36.3\%) survived to hospital discharge. There were no significant differences between early $(\leq 24 \mathrm{~h})$ or late catheterization $(>24 \mathrm{~h})$ groups regarding age, weight, RACHS-1 score, type of catheterization procedure, the indication of ECMO, duration on mechanical ventilation, ICU stay, or hospital stay.

Interestingly, the early catheterization group had a less pulmonary injury, shorter duration on ECMO, more successful weaning from ECMO and more survival to hospital discharge compared to the late group. 
Notably, the late group comprised more patients with single ventricle physiology. Table 2 summarizes ECMO data of all patients, early and late catherization groups. 
Table 2

ECMO data and outcome of studied groups

\begin{tabular}{|c|c|c|c|c|}
\hline & $\begin{array}{l}\text { All } \\
\text { patients } \\
(n=60)\end{array}$ & $\begin{array}{l}\text { Early } \\
\text { catheterization } \\
(n=37)\end{array}$ & $\begin{array}{l}\text { Late } \\
\text { catheterization } \\
(n=23)\end{array}$ & $P$ value \\
\hline Age, days & $\begin{array}{l}196(46- \\
870)\end{array}$ & $210(62-561)$ & $150(40-1095)$ & 0.903 \\
\hline Weight, Kg & $5(3-10)$ & $5(3-9.5)$ & $4(3-11.6)$ & 0.406 \\
\hline Single ventricle $\mathrm{n}(\%)$ & $31(51.7)$ & 13(35) & $18(65)$ & $0.001^{*}$ \\
\hline $\begin{array}{l}\text { Cardiac surgery to ECMO interval, } \\
\text { hours }\end{array}$ & $2(0-13)$ & $1(0-3.5)$ & $2(1-40)$ & $0.042^{*}$ \\
\hline Time from surgery to ECMO, hours & $\begin{array}{l}20(12.5- \\
48)\end{array}$ & $19(3-20)$ & $72(48-140)$ & 0.0001 \\
\hline Indication of ECMO, n (\%) & & & & 0.507 \\
\hline Failure to wean from CPB & $19(31.7)$ & 13(35.1) & $6(26.1)$ & \\
\hline ECPR & $27(45)$ & $17(45.9)$ & $10(43.5)$ & \\
\hline Low cardiac output & $13(21.7)$ & $7(18.9)$ & $6(26.1)$ & \\
\hline Severe desaturation & $1(1.7)$ & - & $1(4.3)$ & \\
\hline \multicolumn{5}{|l|}{ Complications of ECMO, $n$ (\%) } \\
\hline Pulmonary injury & $22(36.7)$ & $8(21.6)$ & $14(60.9)$ & $0.019^{*}$ \\
\hline Hepatic injury & $10(16.7)$ & $4(10.8)$ & $6(26.1)$ & 0.123 \\
\hline Bleeding tendency & $26(43.3)$ & 13(35.1) & $13(56.5)$ & 0.104 \\
\hline Acute kidney injury & 17(28.3) & $8(21.6)$ & $9(39.1)$ & 0.143 \\
\hline Neurological insults & 17(28.3) & 11(29.7) & $6(26.1)$ & 0.761 \\
\hline Vascular/limb ischemia & $11(18.3 \%)$ & $4(10.8)$ & $7(30.4)$ & 0.086 \\
\hline Sepsis & 19(31.6) & $14(37.8)$ & $5(21.7)$ & 0.258 \\
\hline RACHS-1 score, n (\%) & & & & 0.268 \\
\hline $2-3$ & $30(50)$ & $18(48.6)$ & $12(52.2)$ & \\
\hline $4-5$ & $14(23.3)$ & 11(29.7) & $3(13)$ & \\
\hline
\end{tabular}

Abbreviations: ECMO; extracorporeal membrane oxygenation, CPB: cardiopulmonary bypass, CPR; cardiopulmonary resuscitation, ICU; intensive care unit; RACHS RACHS-1; Risk Adjustment for Congenital Heart Surgery. * statistically significant. 


\begin{tabular}{|c|c|c|c|c|}
\hline & $\begin{array}{l}\text { All } \\
\text { patients } \\
(n=60)\end{array}$ & $\begin{array}{l}\text { Early } \\
\text { catheterization } \\
(n=37)\end{array}$ & $\begin{array}{l}\text { Late } \\
\text { catheterization } \\
(n=23)\end{array}$ & $P$ value \\
\hline 6 & $16(26.7)$ & $8(21.6)$ & $8(34.8)$ & \\
\hline Interventional, $\mathrm{n}(\%)$ & $29(48.3)$ & $21(56.8)$ & $8(34.8)$ & 0.098 \\
\hline Redo surgery, n (\%) & $12(20)$ & $5(13.5)$ & $7(30.4)$ & 0.111 \\
\hline Fluro time, minutes & $20(8-45)$ & $30.5(7-55)$ & $\begin{array}{l}15.5(8.25- \\
35.75)\end{array}$ & 0.405 \\
\hline Duration of ECMO, days & $5(3-8)$ & $4(2-6)$ & $7(5-8)$ & $0.008^{*}$ \\
\hline $\begin{array}{l}\text { Duration of mechanical } \\
\text { ventilation, days }\end{array}$ & $14(8-24)$ & $14(8-24)$ & $15(8-24)$ & 0.927 \\
\hline Duration of ICU stay, days & $17(8-30)$ & $22(12.5-32.5)$ & $16(8-24)$ & 0.239 \\
\hline Hospital stay, days & $23(8-37)$ & $35(12-41)$ & $16(8-31)$ & 0.093 \\
\hline \multicolumn{5}{|l|}{ Outcome, n (\%) } \\
\hline Successful decannulation & $34(56.7 \%)$ & $27(73)$ & $7(30.4)$ & $0.001^{*}$ \\
\hline Survival to hospital discharge & $22(36.3 \%)$ & $20(54.1)$ & $2(8.7)$ & $\begin{array}{l}< \\
0.0001^{*}\end{array}$ \\
\hline \multicolumn{5}{|c|}{ 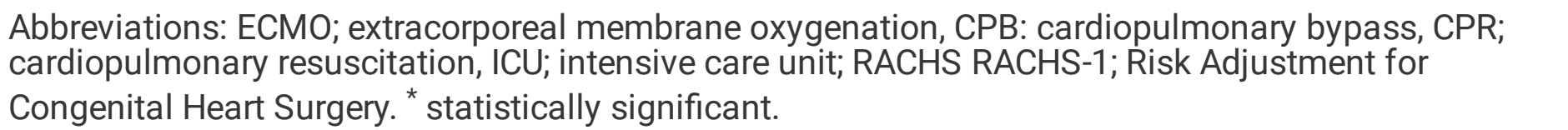 } \\
\hline
\end{tabular}

\section{Cardiac catheterization}

Among this cohort, 31 patients $(51.7 \%)$ underwent diagnostic cardiac catheterizations while 29 patients (48.3\%) performed 33 interventional procedure (4 patients had 2 interventional procedures during the same catheterization procedure). The median interval from ECMO support to cardiac catheterization was 20 hours and the median duration of procedures was 120 minutes.

Echocardiography showed severe ventricular dysfunction in 46 patients $(76.7 \%)$, shunt obstruction in 10 patients $(16.7 \%)$, and pulmonary artery obstruction in 4 patients $(6.7 \%)$. Catheter-related complications were reported in 13 patients $(21.6 \%)$. Most of these complications were related to vascular access (11 patients, $18.3 \%$ ), one patient developed a small tear in the right pulmonary artery after stenting that managed conservatively, the other patient developed tiny cardiac perforation after diagnostic cardiac catheterization. Table 3 summarizes the catheterization data of studied patients. 
Table 3

Cardiac catheterizations data

\section{Catheterization data}

Time of catheterization from ECMO, hours

Procedure duration, minutes

Lesions detected by echocardiography, $\mathrm{n}(\%)$

Severe ventricular dysfunction

Shunt obstruction

Pulmonary artery obstruction

Diagnostic procedures, $\mathbf{n}(\%)$

Coronary artery assessment

Pulmonary arteries assessment

BTS/Sano shunt assessment

Hemodynamic study

Interventional procedures, $\mathrm{n}(\%)$

Coronary angioplasty(balloon/stent)

Pulmonary angioplasty(balloon/stent)

BTS/Sano shunt angioplasty (ballooning+/- stenting

Coil/vascular plug occlusion of collaterals

RVOT stent

Closure of LV-AO fistula

Atrial septostomy

Fontan fenestration

Secondary intervention during the same procedure, $n$

Vascular access, $\mathbf{n}(\%)$

Femoral artery/vein

Jugular vein $(n=60)$

$20(12.5-48)$

$120(40-170)$

10(16.7)

$4(6.7)$

31(51.7)

7

3

5

16

$29(48.3)$ *

8

11

6

2

2

1

2

1

4

56(93.3)

2(6.7)

Abbreviations: ECMO; extracorporeal membrane oxygenation, BTS; Blalock Taussig shunt, RVOT; right ventricle outflow tract, LV; left ventricle, AO; aorta, RPA: right pulmonary artery. ${ }^{*} 29$ Patients underwent 33 interventional procedure with 4 patients underwent 2 procedures in the same settings. 


\begin{tabular}{|lc|}
\hline Catheterization data & (n= 60) \\
\hline Complications, $\mathbf{n}(\%)$ & $13(21.6)$ \\
\hline Vascular injury & $11(18.3)$ \\
\hline Rupture of RPA & $1(1.7)$ \\
\hline Tiny cardiac perforation & $1(1.7)$ \\
\hline $\begin{array}{l}\text { Abbreviations: ECMO; extracorporeal membrane oxygenation, BTS; Blalock Taussig shunt, RVOT; right } \\
\text { ventricle outflow tract, LV; left ventricle, AO; aorta, RPA: right pulmonary artery. *2 29 Patients underwent } \\
33 \text { interventional procedure with 4 patients underwent 2 procedures in the same settings. }\end{array}$ \\
\hline
\end{tabular}

\section{Subsequent cardiac surgery (Redo surgery) after cardiac catheterization}

Based on cardiac catheterization data, 12 patients (20\%) were pushed for a redo surgery. Most of the redo surgery $(4 / 12,33 \%)$ was taking down of cavopulmonary connection $+/$ - insertion of modified Blalock Taussig Thomas shunt. Notably, patients who underwent diagnostic catheterization procedures required more redo surgery and reported less survival compared to patients underwent interventional procedure (Table 4). In other ward, patients underwent diagnostic procedures had higher odds for redo surgery \{OR $6.4,95 \% \mathrm{Cl}(1.27-32.5), \mathrm{p}=0.025)\}$. 
Table 4

Redo surgery after cardiac catheterization

\begin{tabular}{|c|c|c|c|}
\hline & $\begin{array}{l}\text { Diagnostic } \\
\text { group } \\
(n=31)\end{array}$ & $\begin{array}{l}\text { Intervention } \\
\text { group } \\
(n=29)\end{array}$ & $P$ value \\
\hline Redo surgery, n & 10 & 2 & $0.014^{*}$ \\
\hline Type of redo surgery, $n$ & & - & \\
\hline $\begin{array}{l}\text { Take down of cavopulmonary connection }+/- \\
\text { BTS }\end{array}$ & 4 & - & \\
\hline Revision of shunt & 1 & - & \\
\hline Relieve of LVOT or arch obstruction & 2 & - & \\
\hline Coronary surgery & 1 & - & \\
\hline Atrioventricular valve repair & 1 & 1 & \\
\hline Fontan fenestration & - & 1 & \\
\hline Aortic dissection repair & 1 & & \\
\hline Successful decannulation, n (\%) & 14 & 20 & 0.06 \\
\hline Survival to hospital discharge, $n$ & 7 & 15 & $0.019^{*}$ \\
\hline
\end{tabular}

\section{Outcome predictors and survival}

Univariable logistic regression analysis revealed that patients who had biventricular physiology, those had early cardiac catheterization, patients who spent less time on ECMO and those had no bleeding tendency had higher odds for successful weaning from ECMO support. Of note patients connected to ECMO for $\leq 6$ days were 16 times more likely to have successful decannulation. Multivariable logistic regression analysis showed that shorter ECMO duration is associated with successful decannulation. Table 5 demonstrates the predictors of successful weaning from ECMO support. Kaplan Meier survival analysis showed higher survival among patients who had early cardiac catheterization after ECMO support, patients with biventricular physiology and those had a duration on ECMO $\leq 6$ days (Figs. 1-2). 
Table 5

Predictors of successful weaning from ECMO support

\section{Parameters}

Univariable logistic regression analysis

\section{Multivariable logistic regression analysis}

OR $(95 \% \mathrm{Cl})$

$P$ value $\quad$ OR $(95 \% \mathrm{Cl})$

$P$

value

\section{Patients Demographic}

\begin{tabular}{lll} 
Age & $1.00(1.00-1.001)$ & 0.617 \\
\hline Weight & $1.035(0.968-1.107)$ & 0.310 \\
\hline Biventricular physiology & $3.63(1.23-10.73)$ & $0.019^{*}$ \\
\hline $\begin{array}{l}\text { RACHS-1score 2\&3 } \\
\begin{array}{l}\text { Severe cardiac } \\
\text { dysfunction }\end{array}\end{array}$ & $1.80(0.415-7.81)$ & 0.666 \\
\hline
\end{tabular}

\section{Catheterization procedure}

$\begin{array}{lll}\text { Interventional procedure } & 2.69(0.937-7.77) & 0.066 \\ \begin{array}{lll}\text { Time of catheterization } \\ \text { from ECMO support }\end{array} & 0.981(0.966-0.955) & 0.009^{*}\end{array}$
Early cardiac
catheterization
$6.171(1.96-19.430) \quad 0.002^{*}$

Redo surgery

$0.468(0.129-1.692)$

0.247

\section{ECMO indications \&} duration

\begin{tabular}{lllll}
\hline Failure to wean from CPB & $0.889(0.274-2.886)$ & 0.845 & & \\
\hline Duration of ECMO & $0.693(0.549-0.876)$ & $0.002^{*}$ & $0.77(0.609-0.972)$ & $0.020^{*}$ \\
\hline ECMO duration $\leq$ 6days & $16.87(4.44-64)$ & $<$ & $11.61(2.63-51.22)$ & $0.001^{*}$
\end{tabular}

\section{ECMO complications}

\begin{tabular}{lll} 
Lung injury & $2.00(0.616-6.494)$ & 0.249 \\
\hline Acute kidney injury & $2.411(0.766-7.590)$ & 0.133 \\
\hline Liver injury & $2.250(0.563-8.996)$ & 0.251 \\
\hline Bleeding tendency & $0.260(0.088-0.768)$ & $0.015^{*}$
\end{tabular}

Abbreviations: OR; odds ratio, $\mathrm{Cl}$; confidence interval, ECMO; extracorporeal membrane oxygenation, CPB: cardiopulmonary bypass, ${ }^{*}$ statistically significant. 


\begin{tabular}{|lll|}
\hline Parameters & \multicolumn{1}{c|}{$\begin{array}{l}\text { Univariable logistic } \\
\text { regression analysis }\end{array}$} & $\begin{array}{l}\text { Multivariable logistic } \\
\text { regression analysis }\end{array}$ \\
\hline Neurological insult & $0.884(0.283-2.759)$ & 0.832 \\
\hline Sepsis & $2.06(0.657-6.484)$ & 0.215 \\
\hline $\begin{array}{l}\text { Abbreviations: OR; odds ratio, Cl; confidence interval, ECMO; extracorporeal membrane oxygenation, } \\
\text { CPB: cardiopulmonary bypass, * statistically significant. }\end{array}$ & \\
\hline
\end{tabular}

\section{Discussion}

To our knowledge, this study is one of the largest cohorts reporting the outcome of cardiac catheterization performed after congenital heart surgery for patients receiving ECMO support. This study did not include patients who had cardiomyopathy or myocarditis, unlike previous studies. Patients with cardiomyopathy/myocarditis and connected to ECMO support has a better prognosis compared to other patients with congenital heart disease $[2,3,5]$.

In this cohort, approximately half of our patients had single ventricle physiology with RACHS 1socre of 4-6. This proportion is relatively larger compared to other reports $[1,5]$. Other studies reported a similar proportion of patients with univentricular heart [3].

\section{Cardiac catheterization}

Echocardiography plays an important role in the management of patients with critical illness especially those connected to ECMO. The role of echocardiography is not only to evaluate the cardiac functions and cardiac recovery, but it can also be used for identification of residual cardiac lesions of hemodynamic significance after congenital heart surgery[12,13]. Identification of residual cardiac lesions by echocardiography for ECMO patients might be very difficult due to poor acoustic windows associated with opened sternum and poor cardiac pulsations that might underestimate lesion severity [7]. As residual lesions after congenital heart surgery might carry a high risk for poor outcome, cardiac catheterization could provide a detailed evaluation of residual lesions and then a proper decision could be considered for either further intervention during the same catheterization procedure or referral for redo surgery $[3,11,14]$.

Based upon information obtained from cardiac catheterization, $65 \%$ of our patients underwent further interventional procedures either in the form of interventional catheterization during the same procedure $(48 \%)$, subsequent redo surgery ( $16 \%$ ) or both ( 2 patients, $3 \%$ ). Among this cohort one-third of patients underwent diagnostic cardiac catheterization proceeded to redo surgery which might emphasis that not all residual lesions are amenable by cardiac catheterization.

Interventional catheterization might be associated with better survival compared to diagnostic catheterization or redo surgery [3]. Among this report, although patients underwent interventional catheterization had better survival compared to other patients, in multivariate analysis, interventional 
catheterization had no impact on successful decannulation from ECMO. The explanation of this finding might be related to the fact that 8 out of 9 patients who failed decannulation among the interventional group had severe cardiac dysfunction. Kato el reported similar results [1].

In the present study, early cardiac catheterization had a great impact on the clinical outcome. Interestingly, patients who underwent early cardiac catheterization spent less time on ECMO support, had a lower incidence of pulmonary injury and reported more successful decannulation and survival compared to other patients. This may be attributed to the early detection and correction of significant residual lesions causing cardiovascular compromise before irreversible cardiac or end-organ damage as reported by previous studies $[1,3,15]$. Agarwal el reported better ECMO decannulation rate and survival with detection of residual lesions within 3 days from starting ECMO support[7]. Despite better outcome was reported in patients underwent early cardiac catheterization, these findings should be interpreted cautiously. These results could be biased being in patients who had early catheterization the decision for catheterization might be considered after correctable lesions were detected by echocardiography[1]. This also may explain why univariate logistic regression analysis revealed higher odds for successful decannulation in patients with early catheterization while in multivariate regression analysis early catheterization had no impact on successful decannulation. Moreover, a large proportion of early catheterization group had biventricular cardiac anatomy the condition that favour successful decannulation in univariate logistic regression analysis.

There was no reported mortality during patients transfer from PICU to catheterization laboratory or during catheterization procedure like previous reports[2, 4, 5, 12]. Most of the reported complications after cardiac catheterization were related to vascular access. Femoral venous and arterial thrombosis was reported in 6 and 5 patients respectively. All vascular complications were mild and managed conservatively. The rate of serious complications related to catheterization procedures is variable in previous reports $[1,3,5,15]$.

\section{ECMO support}

After congenital cardiac surgery, ECMO is usually used in the setting of low cardiac output status, extracorporeal cardiopulmonary resuscitation and failure of weaning from cardiopulmonary bypass. According to previous reports ECMO is used in approximately $1.5-5 \%$ of cases undergoing congenital cardiac surgery[17-19]. As cardiovascular compromise ended by ECMO support can impair systemic perfusion leading to multiorgan dysfunction, prolonged use of ECMO can also lead to adverse effects to various body organs. ECMO related complications are variable among literatures $[1,4,9,15,20,21]$.

Regarding ECMO complications, the bleeding tendency was the most frequent complications. Moreover, in univariate regression, patients with bleeding tendency had a high risk for unsuccessful decannulation while in multivariate regression analysis complications related to ECMO had no effect on successful weaning from ECMO unlike previous reports[1,9].

\section{Predictors of successful ECMO decannulation and survival}


Predictors of outcome and survival for patients receiving ECMO supported had been widely discussed in previous literature. Predictors associated with better survival commonly reported with myocarditis/cardiomyopathy, biventricular physiology, low inotropic score, absence of associated complications (renal failure, lung injury, neurological complications, bleeding tendency), good lactate clearance, duration of ECMO less than 5 days, and early cardiac catheterization[1, 3, 5, 19, 22-25]. Like previous reports, patients with biventricular physiology, early catheterization, absence of bleeding tendency or lung injury and those with a shorter duration on ECMO $\leq 6$ days had higher odds for successful decannulation in the univariate regression model. In the multivariate regression model, only patients with a shorter duration on ECMO support had higher odds for successful decannulation.

Kaplan Meier survival analysis showed better survival in patients with Biventricular physiology, early cardiac catheterization and those received ECMO support for $\leq 6$ days. Our results were comparable to previously published reports $[1,3,5,10,15]$.

In this cohort successful decannulation was reported in $57 \%$ of patients while survival to hospital discharge was reported in $36 \%$ of patients. Recent cohorts reported a higher percentage of successful decannulation and survival, this discrepancy might be related to different complexities of cardiac lesions, the inclusion of a significant proportion of myocarditis/cardiomyopathy patients who had better prognosis in addition to the unavailability of programs for ventricular assisted device and heart transplantation in our institutions for patients who could not be weaned from ECMO support $[3,5,15]$.

\section{Limitations}

This study was limited by being a retrospective cohort. Besides, this study did not include a control group having similar characteristics of the studied patients without performing cardiac catheterization. With the absence of a control group, the judgement on the impact of cardiac catheterization on the clinical outcome is incomplete. Moreover, the number of patients recruited in this study was relatively small and their demographic features were not homogenous. Futures studies on a large scale of patients recruited from multicentre registry are recommended.

\section{Conclusions}

In patients receiving ECMO support after congenital heart surgery, cardiac catheterization is feasible with an acceptable rate of complications. Shorter duration on ECMO is the most important predictor of successful weaning from ECMO support and survival.

\section{Declarations}

\section{Ethics approval and consent to participate}

The study was approved by the ethical committee of King Abdulaziz university hospital and King Faisal specialist hospital and research centre. Written consents from the patients ' legal guardians were taken 
retrospectively on admission for potential participation in future research and publication. (committee's reference number: 539-20).

\section{Consent for publication}

Available at king Abdulaziz university hospital and King Faisal specialist hospital and research centre.

\section{Availability of data and material}

All data were available at King Abdulaziz University Hospital and King Faisal specialist hospital and research centre.

\section{Competing interests}

The authors declare that they have no competing interests.

\section{Funding}

This work was supported by the Deanship of Scientific Research (DSR), King Abdulaziz University, Jeddah [grant number D-094-140-1441]. The authors, therefore, gratefully acknowledge DSR technical and financial support.

\section{Acknowledgements}

We want to thank Mahmoud Akl and Mosaab Bakkar the cardiopulmonary perfusionists for their cooperation during data collection.

\section{References}

1. Kato A, Lo Rito M, Lee KJ, et al (2017) Impacts of early cardiac catheterization for children with congenital heart disease supported by extracorporeal membrane oxygenation. Catheter Cardiovasc Interv 89:898-905. https://doi.org/10.1002/ccd.26632

2. Booth KL, Roth SJ, Perry SB, et al (2002) Cardiac catheterization of patients supported by extracorporeal membrane oxygenation. J Am Coll Cardiol 40:1681-1686. https://doi.org/10.1016/S0735-1097(02)02343-4

3. Abraham BP, Gilliam E, Kim DW, et al (2016) Early catheterization after initiation of extracorporeal membrane oxygenation support in children is associated with improved survival. Catheter Cardiovasc Interv 88:592-599. https://doi.org/10.1002/ccd.26526

4. Dohain AM, Abdelmohsen G, Elassal AA, et al (2019) Factors affecting the outcome of extracorporeal membrane oxygenation following paediatric cardiac surgery. Cardiol Young 29:1501-1509. https://doi.org/10.1017/S1047951119002634

5. Boscamp NS, Turner ME, Crystal M, et al (2017) Cardiac Catheterization in Pediatric Patients Supported by Extracorporeal Membrane Oxygenation: A 15-Year Experience. Pediatr Cardiol 38:332- 
337. https://doi.org/10.1007/s00246-016-1518-0

6. Bahaidarah S, Al-Ata J, Abdelmohsen G, et al (2020) Cardiac catheterization addressing early postoperative complications in congenital heart surgery-a single-center experience. Egypt Hear J 72:83. https://doi.org/10.1186/S43044-020-00117-6

7. Agarwal HS, Hardison DC, Saville BR, et al (2014) Residual lesions in postoperative pediatric cardiac surgery patients receiving extracorporeal membrane oxygenation support. J Thorac Cardiovasc Surg 147:434-441. https://doi.org/10.1016/j.jtcvs.2013.03.021

8. Kuraim GA, Garros D, Ryerson L, et al (2018) Predictors and outcomes of early post-operative venoarterial extracorporeal membrane oxygenation following infant cardiac surgery. J Intensive Care 6:112. https://doi.org/10.1186/s40560-018-0326-4

9. Roeleveld PP, Mendonca M (2019) Neonatal Cardiac ECMO in 2019 and Beyond. Front Pediatr 7:113. https://doi.org/10.3389/fped.2019.00327

10. Güzeltaş A, Kaşar T, Tanıdır IC, et al (2017) Cardiac catheterization procedures in pediatric patients undergoing extracorporeal membrane oxygenation cardiac catheterization, ECMO. Anatol J Cardiol 18:425-430. https://doi.org/10.14744/AnatolJCardiol.2017.7927

11. DesJardins SE, Crowley DC, Beekman RH, Lloyd TR (1999) Utility of cardiac catheterization in pediatric cardiac patients on ECMO. Catheter Cardiovasc Interv 46:62-67. https://doi.org/10.1002/(SICI)1522-726X(199901)46:1<62::AID-CCD17>3.0.C0;2-9

12. Bautista-Rodriguez C, Sanchez-de-Toledo J, Da Cruz EM (2018) The role of echocardiography in neonates and pediatric patients on extracorporeal membrane oxygenation. Front Pediatr 6:1-13. https://doi.org/10.3389/fped.2018.00297

13. Platts DG, Sedgwick JF, Burstow DJ, et al (2012) The role of echocardiography in the management of patients supported by extracorporeal membrane oxygenation. J Am Soc Echocardiogr 25:131-141. https://doi.org/10.1016/j.echo.2011.11.009

14. Howard TS, Kalish BT, Wigmore D, et al (2016) Association of Extracorporeal Membrane Oxygenation Support Adequacy and Residual Lesions with Outcomes in Neonates Supported after Cardiac Surgery*. Pediatr Crit Care Med 17:1045-1054. https://doi.org/10.1097/PCC.0000000000000943

15. Burke CR, Chan T, Rubio AE, McMullan DM (2017) Early Cardiac Catheterization Leads to Shortened Pediatric Extracorporeal Membrane Oxygenation Run Duration. J Interv Cardiol 30:170-176. https://doi.org/10.1111/joic. 12368

16. Ettedgui JA, Fricker FJ, Park SC, et al (1996) oxygenation. 59-61

17. Mascio CE, Austin EH, Jacobs JP, et al (2014) Perioperative mechanical circulatory support in children: An analysis of the society of thoracic surgeons congenital heart surgery database. J Thorac Cardiovasc Surg 147:658-665. https://doi.org/10.1016/j.jtcvs.2013.09.075

18. Salvin JW, Laussen PC, Thiagarajan RR (2008) Extracorporeal membrane oxygenation for postcardiotomy mechanical cardiovascular support in children with congenital heart disease. Paediatr Anaesth 18:1157-1162. https://doi.org/10.1111/j.1460-9592.2008.02795.x 
19. Sasaki T, Asou T, Takeda Y, et al (2014) Extracorporeal Life Support After Cardiac Surgery in Children: Outcomes From a Single Institution. Artif Organs 38:34-40. https://doi.org/10.1111/aor.12191

20. Maslach-Hubbard A (2013) Extracorporeal membrane oxygenation for pediatric respiratory failure: History, development and current status. World J Crit Care Med 2:29. https://doi.org/10.5492/wjccm.v2.i4.29

21. Shuhaiber J, Thiagarajan RR, Laussen PC, et al (2011) Survival of children requiring repeat extracorporeal membrane oxygenation after congenital heart surgery. Ann Thorac Surg 91:19491955. https://doi.org/10.1016/j.athoracsur.2011.01.078

22. Morris MC, Ittenbach RF, Godinez RI, et al (2004) Risk factors for mortality in 137 pediatric cardiac intensive care unit patients managed with extracorporeal membrane oxygenation. Crit Care Med 32:1061-1069. https://doi.org/10.1097/01.CCM.0000119425.04364.CF

23. Merrill ED, Schoeneberg L, Sandesara P, et al (2014) Outcomes after prolonged extracorporeal membrane oxygenation support in children with cardiac disease - Extracorporeal Life Support Organization registry study. J Thorac Cardiovasc Surg 148:582-588. https://doi.org/10.1016/j.jtcvs.2013.09.038

24. Kumar TKS, Zurakowski D, Dalton $\mathrm{H}$, et al (2010) Extracorporeal membrane oxygenation in postcardiotomy patients: Factors influencing outcome. J Thorac Cardiovasc Surg 140:330-336.e2. https://doi.org/10.1016/j.jtcvs.2010.02.034

25. Ford MA, Gauvreau K, McMullan DM, et al (2016) Factors Associated with Mortality in Neonates Requiring Extracorporeal Membrane Oxygenation for Cardiac Indications: Analysis of the Extracorporeal Life Support Organization Registry Data. Pediatr Crit Care Med 17:860-870. https://doi.org/10.1097/PCC.0000000000000842

\section{Figures}


A

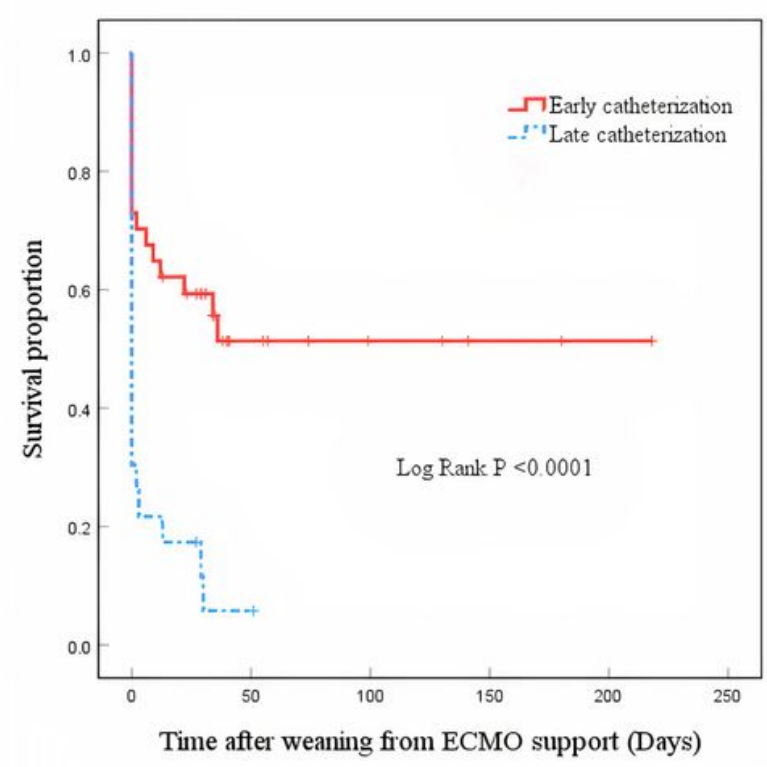

B

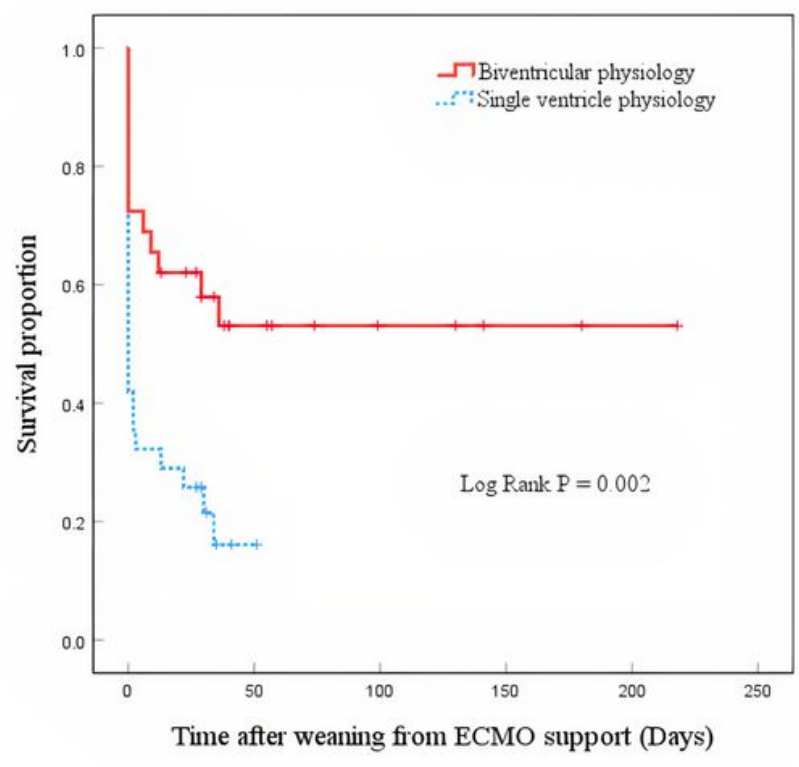

\section{Figure 1}

A- Kaplan Meier survival analysis showing better survival in patients underwent early cardiac catheterization (within 24h from the initiation of ECMO support). B- Kaplan Meier survival analysis showing better survival in patients with biventricular physiology. ECMO; extracorporeal membrane oxygenation. 


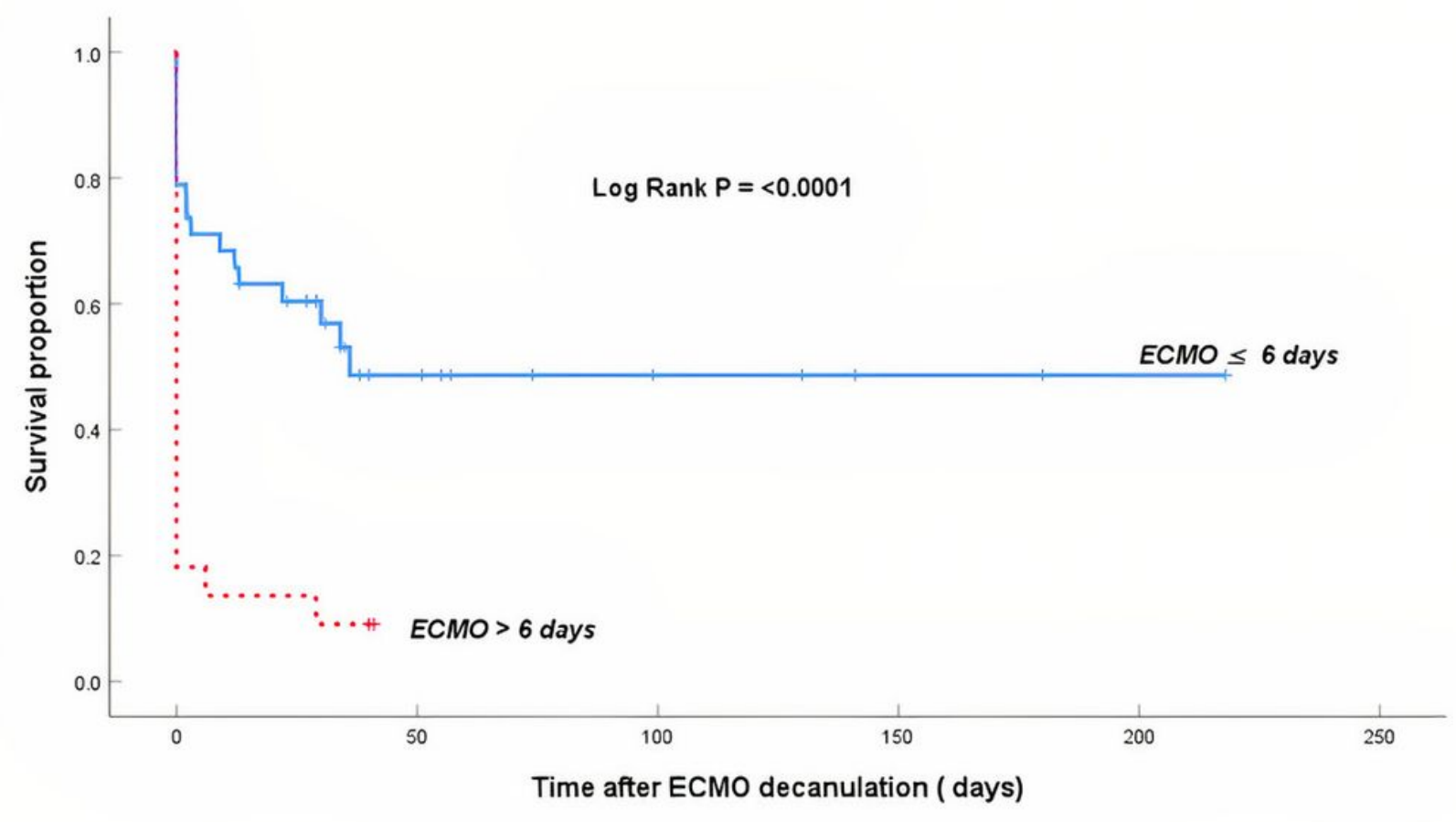

\section{Figure 2}

A- Kaplan Meier survival analysis showing better survival in patients with a shorter duration on ECMO ( $\leq$ 6 days). Receiver operating characteristic (ROC) curve was used to determine the cut-off value of ECMO duration. ECMO; extracorporeal membrane oxygenation. 